\title{
Digital divide research, achievements and shortcomings
}

\author{
Jan A.G.M. van Dijk \\ University of Twente, Department of Communication, Post Box 217, 7500 AE Enschede, The Netherlands
}

\begin{abstract}
From the end of the 1990s onwards the digital divide, commonly defined as the gap between those who have and do not have access to computers and the Internet, has been a central issue on the scholarly and political agenda of new media development. This article makes an inventory of 5 years of digital divide research (2000-2005).

The article focuses on three questions. (1) To what type of inequality does the digital divide concept refer? (2) What is new about the inequality of access to and use of ICTs as compared to other scarce material and immaterial resources? (3) Do new types of inequality exist or rise in the information society?

The results of digital divide research are classified under four successive types of access: motivational, physical, skills and usage. A shift of attention from physical access to skills and usage is observed. In terms of physical access the divide seems to be closing in the most developed countries; concerning digital skills and the use of applications the divide persists or widens.

Among the shortcomings of digital divide research are its lack of theory, conceptual definition, interdisciplinary approach, qualitative research and longitudinal research.
\end{abstract}

(C) 2006 Elsevier B.V. All rights reserved.

\section{Introduction}

In the second half of the 1990s the attention for the subject of unequal access to and use of the new media started to focus on the concept of the so-called digital divide. Before that time more general concepts were used such as information inequality, information gap or knowledge gap and computer or media literacy. The origin of the term digital divide goes back to an unknown American source in the middle of the 1990s and was first used in an official publication by the US Department of Commerce's National Telecommunications and Information Administration (NTIA, 1999). [See Gunkel (2003) for more details about the origin of the term.] The digital divide commonly refers to the gap between those who do and those who do not have access to

E-mail address: Jan.vanDijk@utwente.nl.

URL: http://www.gw.utwente.nl/vandijk. 
new forms of information technology. Most often these forms are computers and their networks but other digital equipment such as mobile telephony and digital television are not ruled out by some users of the term.

The term digital divide probably has caused more confusion than clarification. According to Gunkel (2003) it is a deeply ambiguous term in the sharp dichotomy it refers to. Van Dijk (2003, 2005) has warned against a number of pitfalls of this metaphor. First, the metaphor suggests a simple divide between two clearly divided groups with a yawning gap between them. Secondly, it suggests that the gap is difficult to bridge. A third misunderstanding might be the impression that the divide is about absolute inequalities, that is between those included and those excluded. In reality most inequalities of the access to digital technology observed are more of a relative kind (see below). A final wrong connotation might be the suggestion that the divide is a static condition while in fact the gaps observed are continually shifting (also see below). Both Gunkel and van Dijk have emphasized that the term echoes some kind of technological determinism. It is often suggested that the origins of the inequalities referred to lie in the specific problems of getting physical access to digital technology and that achieving such access for all would solve particular problems in the economy and society. In the last suggestion not only a technological bias but also a normative bias is revealed.

The great merit of the sudden rise of the term digital divide at the turn of the century is that it has put the important issue of inequality in the information society on the scholarly and political agenda. Between the years 2000 and 2004 hundreds of scientific and policy conferences and thousands of sessions on regular conferences have been dedicated to this issue under the call of the term digital divide. In the years 2004 and 2005 attention started to decline. In terms of policy and politics many observers, particularly in the rich and developed countries, reached the conclusion that the problem was almost solved as a rapidly increasing majority of their inhabitants obtained access to computers the Internet and other digital technologies.

From a scientific point of view the concept ran into difficulties; ever more expressions such as 'redefining the digital divide' and 'beyond access' appeared. However, this does not mean that the concept has become an empty cover. On the contrary, it is more of a container concept carrying too many meanings. Therefore, as will be done in this article, one should carefully distinguish between different kinds of digital divide, for example in the shape of a number of types of access.

The ambitious purpose of this article is to list and describe the main achievements and shortcomings of 5 years of digital divide research (2000-2005). Completeness cannot be attained as the database of articles and books on this topic reaches into the thousands by now. The focus of attention will be both theoretical conceptualisation or model building and empirical investigations. Listing the achievements, the most important facts observed will be summarized. Explaining the shortcomings, ways to go forward with empirical research on this issue will be proposed at the end of this contribution. First, a number of basic questions have to be addressed. Why is the presumed problem of the digital divide an interesting or perhaps even important scientific issue?

\section{Three basic questions}

According to Amartya Sen every investigator of a problem concerning equality has to answer the question: "Equality of what?" (Sen, 1992, p. ix). So, a first basic question would be: What inequality does the digital divide concept refer to? A first glance through the social-scientific and economic literature already results in 10 potential answers that can be listed as technological, immaterial, material, social and educational types of (in)equality: 


\begin{tabular}{ll}
\hline Technological & Technological opportunities \\
\hline Immaterial & Life chances \\
Material & Freedom \\
& Capital (economic, social, cultural) \\
Social & Resources \\
& Positions \\
Educational & Power \\
& Participation \\
\hline
\end{tabular}

All of these types of inequality can be observed in digital divide research. The most popular still is technological opportunities because physical access to computers, networks and other technologies has achieved the biggest attention. In considering the demographics that are related to digital divides the three forms of capital and resources have been amply used. In the last few years the focus of attention has also shifted to capabilities and skills, particularly when educational solutions to the digital divide problem are proposed.

The presence of all these types of inequality in current digital divide research shows that classical sociological concepts of inequality could still serve as a background. Concepts of inequality in terms of possessions (Marx), status and profession (Weber) or relationship and power (Simmel and Dahrendorf) still prove to be relevant. However, we will notice that they scarcely play any role in digital divide research as it is relatively poor in theory. We may also ask whether these classical sociological concepts are still adequate to explain inequality in the information society. This general question might lead to two other basic questions.

The suggestion in many digital divide investigations is that this phenomenon is just as new as the technology it is linked to. The divides observed are related to age-old demographics of income, education, age, sex and ethnicity but no comparison is made with other things that are unequally divided in contemporary or past societies. Most often a historical perspective is lacking. The following basic question urges itself: What is exactly new about the inequality of access to and use of information and communication technology as compared to other scarce material and immaterial resources in society?

When this second question is answered in an affirmative way (there are new aspects to be observed) this could lead to a third question: Do new types of inequality rise or exist in the information and network society? If so, what are these types?

These three basic questions will serve as a touchstone for the following summary of results of digital divide research.

\section{Achievements of digital divide research}

\subsection{Types of access}

Digital divide research started with the observation of the number and categories of persons who have a computer and network connection at their disposal. This is a case of having a particular technological opportunity. The technological orientation of this early digital divide research led to the equalization of media or technology access with physical access. Currently, the majority of this research still focuses on physical access. However, 
since the year 2002, an increasing number of researchers suggests to go 'beyond access', to reframe the overly technical concept of the digital divide and to pay more attention to social, psychological and cultural backgrounds. Some have extended the concept of access for this purpose, others have added the concepts of (digital) skills or competencies and media or technology use and applications.

Here, a model that extends the concept of access will be used as a framework to reveal the main achievements of digital divide research (van Dijk, 2003, 2005). See Fig. 1. The succession of types of access that characterizes this model is validated in multivariate research (de Haan and Iedema, in preparation). This succession is elaborated because media or technology access should be seen as a process with many social, mental and technological causes and not as a single event of obtaining a particular technology (Bucy and Newhagen, 2004). In this model material access is preceded by motivational access and succeeded by skills access and usage access. When the full process of technology appropriation is completed, according to this ideal scheme, a new innovation arrives and the process starts again, wholly or partly.

The concept of material access to appear comprises physical access and other types of access that are required to reach complete disposal and connections such as conditional access (subscriptions, accounts, pay-per-view). The concept of skills access is divided into three types of skills that often assume the following order: first a computer user has to acquire operational skills, then s(he) has to develop and apply information skills and finally strategic skills (the capacity to use computer and network sources as means for particular goals in society). Usage access is the final stage and ultimate goal of the process of technological appropriation in the shape of particular applications.

\subsection{Material access}

I will start with the research that has produced data about material access because this was the predominant focus of attention until fairly recently. The largest part of digital divide research is devoted to the observation of divides of physical access to personal computers and the Internet among demographical categories that are obvious in this respect: income, education, age, sex and ethnicity. The first nation-wide surveys in the developed countries at the end of the 1990s and the turn of the century all showed growing gaps of access between people with high and low income

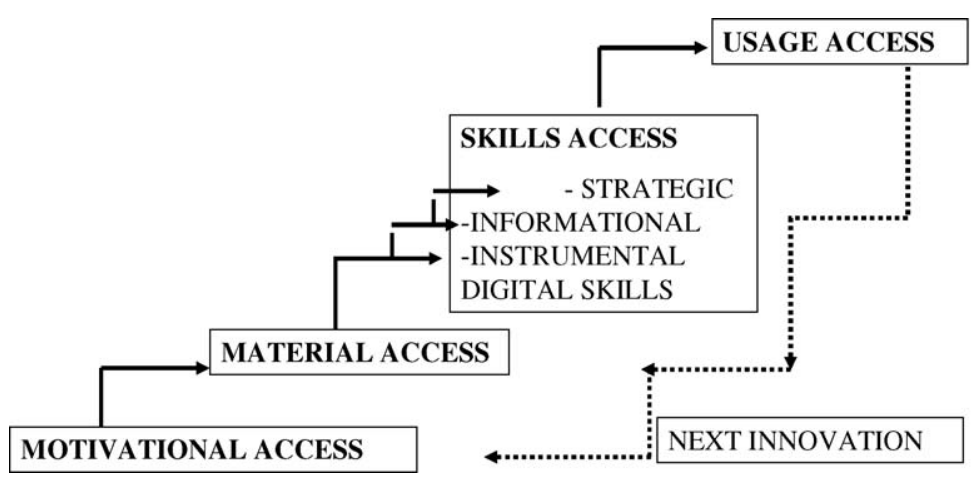

Fig. 1. A cumulative and recursive model of successive kinds of access to digital technologies. Source: van Dijk (2005), p. 22 . 
or education and majority ethnicities as compared to minority ethnicities. However, the gender physical access divide closed in those years, although complete closure only happened in the Northern American and North-Western European countries. Considering age the relationship is curved: physical access culminates in the age group of 25-40 to sharply decline afterwards. Clearly, the youngest generation and women benefit from the household possession of computers, as households are the most familiar survey unit of measurement. The best representative surveys of that period are the first four American NTIA reports (NTIA, 1995, 1998, 1999, 2000, 2002), parts of the annual Eurobarometers (see http://europa.eu.int/comm/ public_opinion/index_en.htm) summarized by the SIBIS-project (www.sibis-eu.org), and two OECD-reports $(2000,2001)$. From the years 2000-2002 onwards the physical access divides in the northern developed countries started to decline as the categories with high income and education reached a partial saturation and people with lower income and education started to catch up (NTIA, 2002; Horrigan and Rainie, 2002a,b; Eurobarometer 56-63, 2001-2005). However, in the developing countries the physical access divide kept widening and is still widening (United Nations Statistics Division, 2004; van Dijk, 2005). In 2000 Norris (2001) surveyed the extent of access to and use of the Internet in 179 nations across the world. A global divide appeared to be evident between industrialized and developing societies. A social divide was apparent between rich and poor within each nation. And within the online community, evidence for a democratic divide was emerging between those who do and do not use Internet resources to engage, mobilize and participate in public life.

Probably, the path of the physical access divide follows the familiar S-curve of the adoption of innovations. However, the path is much more complex and differentiated among groups of the population than the S-curve projects and there are serious problems with mainstream diffusion theory considering computer and Internet technology (see van Dijk, 2005, p. 62-65). One of these problems is treated by Norris (2001) who makes a distinction between a normalization and a stratification model of diffusion. In the normalization model it is presupposed that the differences between groups only increase in the early stages of adoption and that differences disappear with saturation in the last stages. The stratification model assumes that (1) there is a different point of departure of the access curve for the higher and the lower social strata and (2) a different point of arrival: for some strata it might never reach $90-100 \%$.

The two models lead to quite different projections of the evolution of the digital divide from the current situation. Fig. 2 compares the curves of adoption of the highest and the lowest social strata in the developed countries and it suggests a potential trend. Fig. 2 shows how the curves are becoming more convex suggesting the (almost complete) closure of the physical access divide if a normalization model applies, and the continuation of a gap in case the stratification model applies.

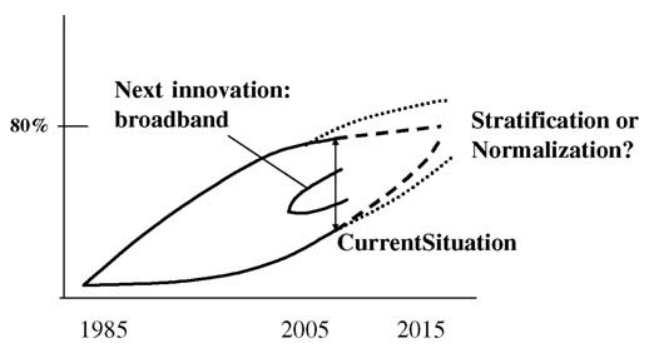

Fig. 2. Real and potential trend of the digital divide in terms of physical access to computers and the Internet according to a stratification model versus a normalization model of development. Source: van Dijk (2005), p. 68. 
At the time of writing (2005) I would estimate from all the available statistics that there is still a gap of about $50 \%$ between the highest and the lowest social strata (90\% diffusion as compared to $40 \%$ diffusion) in the most developed countries and that in these countries approximately 25-30\% of the total population still has no home access to computers and the Internet at all. In less developed countries this figure swiftly increases to reach a majority and in Third World countries it is a vast majority of 90,95 or even more percent of the population.

What are the most important background characteristics of the physical access divide? Usually they are presented in descriptive statistics of simple correlations. Then it appears that the highly correlated variables of income, education and occupation are the most important ones. Multivariate regression analyses with structural equation models are much less frequent. Such analysis was made in a large-scale representative Dutch survey in 2000 (van Dijk, L. et al., 2000) later summarized in English (de Haan, 2003). It appeared at that time that income was the most important factor for physical access, followed by age (with as mentioned above its curvilinearity), and then education. With the declining costs of computer equipment in recent years the importance of income has been somewhat reduced but it remains the most important factor for material access because total computer and Internet access costs (peripherals, printing costs, software, subscriptions and connection costs) barely diminish. In poor countries lack of income remains the decisive barrier.

The background variables mentioned reveal that types of inequality such as those based on differences in economic, social, and cultural capital are prevalent in digital divide research aimed at explaining differences in physical access. Other researchers defend a resource based approach (van Dijk, 2000; de Haan, 2003; Dutta-Bergman, 2005). Van Dijk (2005) combines a resource based and a social position or network approach. Differences in physical access are related to a distribution of resources (temporal, mental, material, social and cultural) that in turn can be accounted for by ascribed categories such as age, sex, intelligence, personality and ability and positions in society (labour, education and household position). The main consequence of the digital divide, defined in this way, is more or less participation in the most relevant fields of society (economy, politics, culture, spatial mobility, social institutions, social networks and communities). For example, as Dutta-Bergman shows, a particular type of physical access, (easy) public Internet access in communities is related to participation in this community.

\subsection{Motivational access}

Prior to physical access comes the wish to have a computer and to be connected to the Internet. Many of those who remain at the 'wrong' side of the digital divide have motivational problems. With regard to digital technology it appears that there are not only 'have-nots', but also 'wantnots'. In the age of the Internet hype this was a much neglected phenomenon. Research among non-users and the unconnected is relatively scarce. At the turn of the century German and American surveys (ARD-ZDF, 1999a and NTIA, 2000) showed that the main reasons for the refusal to use computers and get connected to the Internet were:

- no need or significant usage opportunities;

- no time or liking;

- rejection of the medium (the Internet and computer games as 'dangerous' media);

- lack of money;

- lack of skills. 
In several European and American surveys reported between 1999 and 2003 it was revealed that half of the respondents unconnected to the Internet at that time explicitly responded that they would refuse to get connected, for the list of reasons just mentioned (e.g. ARD-ZDF, 1999b and a Pew Internet and American Life survey (Lenhart et al., 2003).

One of the most confusing myths produced by popular ideas about the digital divide is that people are either in or out, included or excluded. The Pew survey revealed that the Internet population is ever shifting (Lenhart et al., 2003). First, there are so-called intermittent users: in 2002 between 27 and 44\% of American Internet users stated that they had gone offline for extended periods. A second, often unnoticed, group is the dropouts that lost connection to the Internet. Their number was $10 \%$ of the American population in 2002. The next group is the 'netevaders' (about $8 \%$ in this survey) that simply refuses to use the Internet, whether they have the resources or not. Among them we find older managers ordering their secretaries to use email and search the Internet and persons being proud of not using that 'filthy medium' or computers that are related to 'women's work').

The ever-shifting Internet population focuses our attention on a second, perhaps even more influential myth produced by the misleading dichotomy of the digital divide. This is the assumption that those who have a computer or Internet connection are actually using it. Many presumed users use the computer or the Internet only once a week or a couple of times a month, a few people never use them. Measuring computer and Internet access in survey questions often conflates possession or connection with use or usage time. Time diary studies and the like show much larger differences or divides between categories of people as will be argued with usage access below (see Section 3.5, below). Here the (allegedly vanished) physical access gap of gender in some Western countries appears to be all but closed. On the contrary, with actual computer and Internet usage gender differences are getting more pronounced.

The factors explaining motivational access are both of a social or cultural and a mental or psychological nature. A primary social explanation is that "the Internet does not have appeal for low-income and low-educated people" (Katz and Rice, 2002, p. 93). To dig deeper into the reasons for this lack of interest it seems appropriate to complete large-scale surveys with qualitative studies in local communities and cultural groups. This was done for instance by Laura Stanley in a San Diego study in poor Latino and African American working class neighbourhoods (Stanley, 2001), and by the University of Texas in poor communities of Austin (Rojas et al., 2004). They discovered the importance of traditional masculine cultures (rejecting computer work that is not 'cool' and 'something girls do') and of particular minority and working class lifestyles.

However, most pronounced are mental and psychological explanations. Here the phenomena of computer anxiety and technophobia come forward. Computer anxiety is a feeling of discomfort, stress, or fear experienced when confronting computers (Brosnan, 1998; Chua et al., 1999; Rockwell and Singleton, 2002). Technophobia is a fear of technology in general and a distrust in its beneficial effects. According to a representative UCLA survey of 2003 more than $30 \%$ of new American Internet users reported that they were moderately to highly technophobic and the same applied to $10 \%$ of experienced Internet users (UCLA, 2003, p. 25). Computer anxiety and technophobia are major barriers of computer and Internet access, especially among seniors, people with low educational level and a part of the female population. These phenomena do not completely disappear with a rise in computer experience.

The continuation of anxiety is partly explained by personality characteristics. The Big Five personality dimensions (agreeableness, conscientiousness, neuroticism, extraversion, and openness) are known to be related to computer use, attitude and stress. For example, 
neuroticism aggravates problems experienced in approaching and using computers and extraversion alleviates them. See Hudiburg (1999) and Finn and Korukonda (2004) for the personality dimensions related to computer use.

\subsection{Skills access}

After having acquired the motivation to use computers and some kind of physical access to them, one has to learn to manage the hardware and software. Here the problem of a lack of skills might appear according to the model in Fig. 1. This problem is framed with terms such as 'computer, information or multimedia literacy' and 'computer skills' or 'information capital'. Steyaert (2000) and van Dijk (1999, 2003, 2005) introduced the concept of 'digital skills' as a succession of three types of skill. The most basic are 'instrumental skills' (Steyaert) or 'operational skills' (van Dijk), the capacities to work with hardware and software. These skills have acquired much attention in the literature and in public opinion. The most popular view is that skills problems are solved when these skills are mastered. However, many scholars engaged with information processing in an information society have called attention to all kinds of information skills required to successfully use computers and the Internet. Steyaert distinguishes between 'structural skills' and 'strategic skills'. van Dijk proposes a comparable distinction between 'information skills' and 'strategic skills'. Information skills are the skills to search, select, and process information in computer and network sources. Two types of information skills are required: formal information skills (ability to work with the formal characteristics of computers and the Internet, e.g. file and hyperlink structures) and substantial information skills (ability to find, select, process, and evaluate information in specific sources following specific questions). See van Dijk (2005, p. 81). Strategic skills can be defined as the capacities to use computer and network sources as the means for particular goals and for the general goal of improving one's position in society.

Research on these kinds of digital skills is scarce. Actually, the only data available bear on people's command of operational skills. Institutions offering computer courses sometimes record the achievements of course takers. Some national surveys that ask population samples to report about their computer and Internet skills are available (for example van Dijk, L. et al., 2000; Park, 2002; UCLA, 2001, 2003). Mostly, they only pay attention to the command of hardware and software, not to information skills. However, the biggest problem of these surveys is validity: are self-reports valid measurements of actual skills possessed? In one of the UCLA Internet studies $63 \%$ of respondents declared they had good or excellent abilities to use the Internet (UCLA, 2003, p. 24), while a much more specific Dutch measurement of (mainly operational) digital skills by self-reports showed that actually only working young males below 40 reached a 6 on a nine-point scale and other groups a 2 to 5 (CBS/SCP, 2001).

The other, much better, scientific approach is to organize performance tests in controlled environments. So far, the only experiments we know of are those by the new media researcher and sociologist Eszter Hargittai. For her dissertation, she conducted a series of experimental tests with American user groups charged with the task of finding particular types of information on the Internet (Hargittai, 2002, 2003, 2004). Thus, she was able to measure both formal and substantial information skills. Subjects were selected and matched according to age, sex and education. Enormous differences were found in the measure of accomplishment and time needed to finish these tasks. Only half of the experimental group was able to complete all tasks in the first experiment, but for some subjects time required for a particular task was a few seconds while others needed 7-14 min (Hargittai, 2002). 
The general impression of these skills investigations, both surveys and tests is (1) that the divides of skills access are bigger than the divides of physical access and (2) that, while physical access gaps are more or less closing in the developed countries, the skills gap (in particular, regarding information skills) tends to grow. A striking result is that those having a high level of traditional literacy also possess a high level of digital information skills (van Dijk, L. et al. 2000; de Haan, 2003). These skills appear to be more important for computer and Internet use than technical know how and the capacity to deal with numerical data.

Another striking result from digital skills research is that people learn more of these skills in practice, by trial and error, than in formal educational settings (de Haan and Huysmans, 2002; van Dijk, 2005). The social context and social networking of computer and Internet users appear to be decisive factors in the opportunities they have for learning digital skills.

Asking for differences in strategic skills has not been an explicit research question yet. Talking about these skills means making a transition to the actual usage of digital media and how this usage may lead to more or less participation in several fields of society.

\subsection{Usage access}

Actual usage of digital media is the final stage and ultimate goal of the total process of appropriation of technology that is called access in this article. Having sufficient motivation, physical access and skills to apply digital media are necessary but not sufficient conditions of actual use. Usage has its own grounds or determinants. As a dependent factor it can be measured in at least four ways:

1. usage time;

2. usage applications and diversity;

3. broadband or narrowband use;

4. more or less active or creative use.

Current computer and Internet use statistics are notoriously unreliable with their shifting and divergent operational definitions of use (see below), most often made by market research bureaus. They only give some indication of how much actual use differs from physical access. For example, according to the market researcher Nielsen/NetRatings, between one-third and twothirds of those connected to the Internet in a large number of countries are using the Internet only once a month (see: http://www.clickz.com/stats/web_worldwide/). Though one may doubt these low figures, most observers would agree that actual use diverges from potential use. More exact measures of daily, weekly or monthly Internet use are reported in the annual surveys of the Pew Internet and American Life Project (www.pewinternet.org) and the UCLA Internet Reports (www.digitalcenter.org). However, the most valid and reliable estimations of actual usage time are made in detailed daily time diary studies that are representative for a particular country. They sometimes produce striking results. For example, the Dutch Social and Cultural Planning Agency found in a 2001 time diary study that the number of weekly hours of computer and Internet use of males was double that of females (SCP, 2001). The gender physical access gap may have almost been closed in the Netherlands, but this certainly does not apply to the usage gender gap.

Comparable results appear in surveys relating usage applications to demographic characteristics of users (see for the US Howard et al., 2001; Horrigan and Rainie, 2002a; UCLA Center for Communication Policy, 2003). Specific social categories of users prefer different kinds of applications. These studies all show significant differences among users with 
different social class, education, age, gender and ethnicity. Some investigators (van Dijk, 1999, 2000, 2003, 2004; Bonfadelli, 2002; Park, 2002; Cho et al., 2003) even perceive a so-called usage gap between people differing in social class and education that is comparable to the phenomenon of the knowledge gap that has been observed from the 1970s onwards. While the knowledge gap is about the differential derivation of knowledge from the mass media, the usage gap is a broader thesis about a differential use of whole applications in daily practices. Van Dijk (2005, p. 130) observes 'the first signs of a usage gap between people of high social position, income, and education using the advanced computer and Internet applications for information, communication, work, business, or education and people of low social position, income, and education using simpler applications for information, communication, shopping, and entertainment'.

Usage of narrowband versus broadband connections appears to have a strong effect on usage time and on the type and range of applications. People with broadband connections take much more advantage of the opportunities of the new media. They are much less deterred by the costs of connection time; they use many more applications and for a longer time (Horrigan and Rainie, 2002b; UCLA, 2003). A 'broadband elite' arises that uses the connection for 10 or more online activities on a typical day (Horrigan and Rainie). Finally, broadband stimulates a much more active and creative use of the Internet (Idem).

Despite its image of being interactive, most Internet usage, apart from emailing, is relatively passive and consuming. Active and creative use of the Internet, that is, contributions to the Internet by users themselves, is a minority phenomenon. Active contributions are publishing a personal website, creating a weblog, posting a contribution on an online bulletin board, newsgroup or community and perhaps, in a broad definition, exchanging music and video files. In USA, 20\% of online Americans produced such content in 2002 in a narrow definition and $44 \%$ in 2003 in a broad definition (Lenhart et al., 2003, 2004).

A general conclusion from a number of investigations of usage is that, increasingly, all familiar social and cultural differences in society are reflected in computer and Internet use.

\section{Starting to find answers to the basic questions}

In light of the information of access types, we may consider whether and to what extent current digital divide research has addressed the basic questions mentioned in Section 2. A general qualification is that it has only started to address these issues. This is due to the theoretical weakness of digital divide research, the main shortcomings of which will be discussed in the next section. In digital divide research, the notion of inequality mostly refers to inequality of technological opportunities. This is due to the fact that in the first years of digital divide research priority was given to physical access; besides, technological determinism, the view that everything could be fixed through a technological approach, played a role. From 2002 onwards the calls to go beyond (physical) access have led to social scientific, communication and educational research emphasizing inequality of social, cultural and information capital and resources. Additionally, some have called attention to the inequality of positions and power in social networks that could lead to unequal participation in several fields of society. Subsequently, attention shifted to inequalities of skills, capabilities and interests when research started to deal with the large-scale incorporation of digital media in daily life, in this way reflecting all social and cultural differences in society.

Contemporary digital divide research has much more difficulty in providing answers to the second basic question, the question of what is exactly new about the inequality of access to and use of information and communication technology as compared to other scarce material and 
immaterial resources in society. In seeking to answer this question, we presume the characterization of contemporary society as an information society to be fruitful. In that context we can call attention to the effects of information as a source of inequality. The literature refers to three effects of information that serve as a basis of inequality.

First, information is considered to be a primary good (see Rawls, 1971 and Sen, 1985). Primary goods are material and immaterial goods that are so essential for the survival and self-respect of individuals that they can not be exchanged for other goods, such as a basic (survival) level of income, life chances, freedoms and fundamental rights. Information has become a primary good in contemporary society even though the minimum amount that is required appears hard to assess and is likely to differ according to the type of society. Not all people possess such a minimum, for example (functional) illiterates. When digital media are gradually replacing and surpassing analogue print media, traditional illiterates are joined by a new category, the 'digital illiterates'

Even more important than this absolute type of inequality in processing information is the increasing role of relative differences in possessing and controlling information in an information society. According to Castells (1996) information has become an independent source of productivity and power. Van Dijk (2005) adds that the relative differences between social categories, that were already unequal in terms of 'old' types of resources and capital, are amplified by the use of digital media. This happens because the control of positions in an increasingly complex society and the possession of information and strategic skills to acquire and maintain these positions are increasingly unequally divided. In this way digital media usage contributes to new types of absolute and relative inequality on top of the old ones, or they reinforce them.

This is backed by another characteristic of information. It can also be a positional good (Hirsch, 1976). These are goods that, by definition, are scarce. Despite the phenomenon of information overload in society, information can be scarce in particular circumstances. Some positions in society create better opportunities than others in gathering, processing and using valuable information. This condition appears to be become increasingly important in the nascent network society (van Dijk, 1999, 2005). In this kind of society, the positions people have in social and media networks determines their potential power. As the importance of the media networks created by computers and their networks increases in contemporary society, having no position in these networks, or a marginal one, entails social exclusion. Contrary to that, those that are very much included because they do have a central position, the so-called information elite, increase their power, capital and resources. So, this is a second effect of the possession of information in the information and network society that amplifies old inequalities.

A third amplifying effect comes from information as a source of skills. Investigators of the Dutch CPB (Netherlands Bureau of Economic Policy Analysis) have shown in an international comparative and historical survey of labour markets that the successful appropriation of ICTs creates a so-called 'skills premium' (Nahuis and de Groot, 2003). On the basis of very extensive quantitative longitudinal data of a large number of countries they argue that the skills premium of having ICT skills is one of the main causes of increasing income inequality in these countries in the 1980s and 1990s.

\section{Shortcomings of digital divide research and ways to compensate them in empirical research}

Attempts to answer the basic questions discussed above are very scarce. The main reason is that digital divide research suffers from a lack of theory. In the past 5-10 years, it has remained at 
a descriptive level, emphasizing the demographics of income, education, age, sex, and ethnicity. The deeper social, cultural, and psychological causes behind the inequality of access have not been addressed so far. The most conspicuous fact is that the digital divide has not been discussed against the background of a general theory of social inequality, other types of inequality, or even a concept of human inequality in general. A theoretical background that has played a minor role is the diffusion of innovations theory. (See Mason and Hacker (2003) for the small role of communication theory.) However, many criticisms of innovations theory can be listed when applied to digital divide research (see van Dijk, 2005, p. 62-66). Its most important popular expressions, the so-called S-curve and the trickle-down principle of the adoption of innovations from the higher to the lower social strata -, pose serious problems, and they bear a determinist flavour. Recent digital divide research has reached the stage of causal model building and structural equation modelling. This is the most important way to go ahead. However, for this purpose explicit theories are urgently required.

A second problem is the lack of interdisciplinary research. Following the usual demographics and the emphasis on physical access, there is a preponderance of sociological and economic research. Contributions from psychology and even from communication and education studies are relatively small (Bucy and Newhagen, 2004; Mason and Hacker, 2003). However, the summary of achievements of digital divide research in Section 3 has shown that the digital divide cannot be understood without addressing issues such as attitudes toward technology (e.g. technophobia and computer anxiety), the channels used in new media diffusion, educational views of digital skills, and cultural analyses of lifestyles and daily usage patterns.

The next lacuna is a lack of qualitative research. Most digital divide research is based on quantitative data collection and tries to describe the large picture of the problem. Although this produces vast amounts of correlations, it does not bring forward the precise mechanisms explaining the appropriation and division of the technology concerned in everyday life. Qualitative research, such as that of Laura Stanley in poor San Diego communities mentioned above is able to show how attitudes to computer and Internet use are created and how inequalities of motivational, physical, skills and usage access are maintained in particular small individual and group settings where interpersonal relations and particular cultures dominate.

The fourth basic problem with digital divide research is that it is rather static, both in arguments produced and in empirical data used. There is a lack of dynamic approach (van Dijk and Hacker, 2003). For example, according to the trickle-down principle of diffusion theory, present technologies such as personal computers and an Internet connections will soon be available to all because they are getting cheaper and easier to use by the day. Such reasoning seems dynamic, but actually it is static, because one forgets that the technology is changing fast and that the people who first adopted it do not stop to obtain new technologies and skills. As soon as the laggards have caught up, the forerunners have already moved further ahead and are using a more advanced technology. Concerning the data used in digital divide research, annual crosssections in time are common, but longitudinal data are scarce. They are only starting to appear now in regular or annual replicated survey research.

A fifth flaw of digital divide research is insufficient attention paid to the consequences of the digital divide(s) observed. Are these consequences to be sought in more or less participation in several fields of society, or in more or less utilization of new technological opportunities? The solution of this problem requires answers to the three basic questions discussed in this article. Simultaneously it calls for extensive empirical research, first of all longitudinal research and multivariate analyses, of the relationships between all kinds of access explained above and social behaviour. 
A final and most serious omission of current digital divide research is the lack of conceptual elaboration and definition. Filling this gap is the most urgent task. Unfortunately, even the most basic terms and concepts are still ill defined. The most important seems to be the concept of access itself (see Bucy and Newhagen, 2004). Others are exact definitions of the technology concerned and the way it is used. What exactly is a computer and an Internet connection? What precisely is having access to the Internet and what parameters are insufficient to the phrase having access? What is computer literacy or what are the so-called digital skills and similar terms? What exactly is Internet use? Better definitions of these concepts backed by theory and valid operational definitions for empirical research would considerably support the achievements of digital divide research in the next 5 years.

\section{References}

ARD/ZDF-Arbeitsgruppe Multimedia, 1999a. ARD/ZDF-online-studie 1999: Wird online alltagsmedium? [ARD/ZDF online study: Is online becoming an everyday medium?]. Media Perspektiven, 1999. Nr. 8, 388-409.

ARD/ZDF-Arbeitsgruppe Multimedia, 1999b. Nichtnutzer von online: Einstellungen und zugangsbarrieren. Ergebnisse der ARD/ZDF-offline-studie 1999 [Online nonusers: Attitudes and access barriers. Results of the ARD/ZDF offline study 1999]. Media Perspektiven, 1999. Nr. 8, 415-422.

Bonfadelli, H., 2002. The Internet and knowledge gaps: a theoretical and empirical investigation. European Journal of Communication 17 (1), 65-84.

Brosnan, M.J., 1998. The impact of computer anxiety and self-efficacy upon performance. Journal of Computer Assisted Learning 14, 223-234.

Bucy, E., Newhagen, J. (Eds.), 2004. Media Access: Social and Psychological Dimensions of New Technology Use. LEA, London.

Castells, M., 1996. The Information Age: Economy, Society and Culture. Vol. I. The Rise of the Network Society. Blackwell, Oxford, England.

CBS/SCP (Centraal Bureau voor de Statistiek/Sociaal-Cultureel Planbureau), 2001. ICT-Pilot 2001. CBS/SCP, Rijswijk, Netherlands.

Cho, J., de Zúñiga, H., Rojas, H., Shah, D., 2003. Beyond access: the digital divide and Internet uses and gratifications. IT \& Society 1 (4), 46-72.

Chua, S.L., Chen, D.T., Wong, A.F.L., 1999. Computer anxiety and its correlates: a meta-analysis. Computers in Human Behavior 15, 609-623.

de Haan, J., Huysmans, F., 2002. Van huis uit digitaal: Verwerving van digitale vaardigheden tussen thuismilieu en school [Raised digital: The acquisition of digital skills between home and school environment]. The Hague: Sociaal en Cultureel Planbureau. Retrieved June 25, 2004. from http:/www.scp.nl/publicaties/boeken/9037700896.shtml.

de Haan, Jos, 2003. IT and social inequality in the Netherlands. IT \& Society 1 (4), $27-45$.

de Haan, Jos, Iedema, J. (in preparation). Models of access to the information society. New Media \& Society.

Dutta-Bergman, M., 2005. Access to the Internet in the context of community participation and community satisfaction. New Media and Society 7, 89-109.

Eurobarometer, 2002-2005. Standard Eurobarometer 56-63. Retrieved September 8, 2005, from http://europa.eu.int/ comm/public_opinion/index_en.htm.

Finn, S., Korukonda, A.R., 2004. Avoiding computers: does personality play a role? In: Bucy, E., Newhagen, J. (Eds.), Media Access: Social and Psychological Dimensions of New Technology Use. LEA, London, pp. 73-90.

Gunkel, D., 2003. Second thoughts: toward a critique of the digital divide. New Media \& Society 5 (4), $499-522$.

Hargittai, Eszter, 2002. The second-level digital divide: differences in people's online skills. First Monday: PeerReviewed Journal on the Internet, 7(4). Retrieved August 31, 2004, from http://firstmonday.org/issues/issue7_4/ hargittai/.

Hargittai, Eszter, 2003. The digital divide and what to do about it. In: D.C. Jones (Ed.). The New Economy Handbook. Academic Press, San Diego, CA. Retrieved August 31, 2004, from http://www.princeton.edu/ eszter/research/c04digitaldivide.html.

Hargittai, Eszter, 2004. How wide a web? Social inequality in the digital age. Ph.D. dissertation, Princeton, NJ, Princeton University, Sociology Department.

Hirsch, F., 1976. The Social Limits to Growth. Routledge \& Kegan Paul, London. 
Horrigan, J., Rainie, L., 2002a. Getting serious online: as Americans gain experience, they pursue more serious activities. Washington DC: Pew Internet and American Life Project. Retrieved August 28, 2004, from http://www.pewinternet. org.

Horrigan, J., Rainie, L., 2002b. The broadband difference: how online behavior changes with high-speed Internet connections. Washington DC: Pew Internet and American Life Project. Retrieved August 28, 2004, from http:// www.pewinternet.org.

Howard, P., Rainie, L., Jones, S., 2001. Days and nights on the Internet: the impact of a diffusing technology. In: Wellman, B., Haythornthwaite, C. (Eds.), The Internet in Everyday Life. Blackwell, Oxford, England, pp. 45-73.

Hudiburg, R.A., 1999. Preliminary investigation of computer stress and the big five personality factors. Psychology Reports 85, 473-480.

Katz, J.E., Rice, R.E., 2002. Social Consequences of Internet Use, Access, Involvement and Interaction. MIT Press, Cambridge, MA.

Lenhart, A., Horrigan, J., Rainie, L., Allen, K., Boyce, A., Madden, M., et al., 2003. The ever-shifting Internet population: A new look at Internet access and the digital divide. Washington, DC: Pew Internet and American Life Project. Retrieved August 28, 2004, from http://www.pewinternet.org.

Lenhart, A., Fallows, D., Horrigan, J., 2004. Content creation online. Washington, DC: Pew Internet and American Life Project. Retrieved August 28, 2004, from http://www.pewinternet.org.

Mason, S., Hacker, K., 2003. Applying communication theory to digital divide research. IT \& Society 5 (5), 40-55.

Nahuis, R., de Groot, H., 2003. Rising skill premia: you ain't seen nothing yet (CPB discussion paper no. 20). The Hague, Netherlands: Centraal Plan Bureau, Netherlands Bureau for Economic Policy Analysis. Retrieved February 7, 2004, from http://ideas.repec.org/p/cpb/discus/20.html.

Norris, P., 2001. Digital Divide, Civic Engagement Information Poverty and the Internet Worldwide. Cambridge University Press, Cambridge, England.

NTIA (National Telecommunications and Information Administration), July 1995. Falling through the Net: A survey of the "have nots" in rural and urban America. Retrieved September 29, 2004, from http://www.ntia.doc.gov/ntiahome/ fallingthru.html.

NTIA (National Telecommunications and Information Administration), 1998. Falling through the Net II: New data on the digital divide. Retrieved September 29, 2004, from http://www.ntia.doc.gov/ntiahome/net2/.

NTIA 1999 (National Telecommunications and Information Administration), 1999. Falling through the Net: defining the digital divide. Retrieved September 29, 2004, from http://www.ntia.doc.gov/ntiahome/fttn99/contents.html.

NTIA 2000 (National Telecommunications and Information Administration), 2000. Falling through the Net II: toward digital inclusion. Retrieved September 29, 2004, from http://www.ntia.doc.gov/ntiahome/fttn00/contents00.html.

NTIA (National Telecommunications and Information Administration), 2002. A nation online: how Americans are expanding their use of the Internet. Retrieved September 29, 2004, from http://www.ntia.doc.gov/ntiahome/dn/ index.html.

OECD, 2000. The digital divide: diffusion and use of ICT's. Paris, OECD.

OECD, 2001. Understanding the digital divide. Paris, OECD.

Park, Han W., 2002. The digital divide in South Korea: closing and widening divides in the 1990s. Electronic Journal of Communication/Revue de Communication Electronique, 12(1 \& 2). Retrieved September 28, 2004, from http:// www.cios.org/www/ejc.

Rawls, J., 1971. Theory of Justice. Harvard University Press, Cambridge, MA.

Rockwell, S., Singleton, L., 2002. The effects of computer anxiety and communication apprehension on the adoption and utilization of the Internet. Electronic Journal of Communication/Revue de Communication Electronique, 12(1). Retrieved June 12, 2004, from http://www.cios.org/www/ejc.

Rojas, V., Straubhaar, J., Roychowdhury, D., Okur, O., 2004. Communities, cultural capital and the digital divide. In: Bucy, E., Newhagen, J. (Eds.), Media Access: Social and Psychological Dimensions of New Technology Use. LEA, London, pp. 107-130.

SCP (Sociaal en Cultureel Planbureau), 2001. Trends in de tijd [Trends in time] The Hague, Netherlands SCP.

Sen, A., 1985. Commodities and Capabilities. North-Holland, Amsterdam.

Sen, A., 1992. Inequality Reexamined. Oxford University Press, Oxford, England.

Stanley, L., 2001. Beyond access. Retrieved March 11, 2004, from www.mediamanage.net/Beyond_Access.pdf.

Steyaert, J., 2000. Digitale vaardigheden: Geletterdheid in de informatiesamenleving [Digital skills: Literacy in the information society]. Rathenau Instituut, The Hague, Netherlands.

UCLA, University of California, Los Angeles, Center for Communication Policy, 2001. The UCLA Internet report 2001: Surveying the digital future, year two. Los Angeles: Author. Retrieved March 2, 2004, from http://www.ccp.ucla.edu/ pages/internet-report.asp. 
UCLA, University of California, Los Angeles, Center for Communication Policy, 2003. The UCLA Internet report: Surveying the digital future, year three. Los Angeles: Author. Retrieved March 2, 2004, from http://www.ccp. ucla.edu/pages/internet-report.asp.

United Nations Statistics Division, 2004. Millennium indicators database: Personal Computers and Internet users per 100 population (ITU estimates). Retrieved March 11, 2004, from http://millenniumindicators.un.org/unsd/mi/mi_ indicator_xrxx.asp?ind_code $=48$.

van Dijk, Jan, 1999. The Network Society: Social Aspects of New Media. Sage Publications, London.

van Dijk, Jan, 2000. Widening information gaps and policies of prevention. In: Hacker, K., van Dijk, J. (Eds.), Digital Democracy: Issues of Theory and Practice. Sage Publications, London, pp. 166-183.

van Dijk, Jan, 2003. A framework for digital divide research. Electronic Journal of Communication/Revue de Communication Electronique, 12(1). Retrieved September 30, 2004, from http://www.cios.org/getfile/vandijk_.

van Dijk, Jan A.G.M., 2004. Divides in succession: possession, skills, and use of new media for societal participation. In: Bucy, E., Newhagen, J. (Eds.), Media Access: Social and Psychological Dimensions of New Technology Use. LEA, London, pp. 233-254.

van Dijk, Jan A.G.M., 2005. The Deepening Divide Inequality in the Information Society. Sage Publications, Thousand Oaks CA/London/New Delhi.

van Dijk, Jan A.G.M., Hacker, K., 2003. The digital divide as a complex and dynamic phenomenon. Information Society 19, 315-326.

van Dijk, Liset, J., de Haan, J., Rijken, S., 2000. Digitalisering van de leefwereld: Een onderzoek naar informatie en communicatietechnologie en sociale ongelijkheid [Digitization of everyday life: A survey of information and communication technology and social inequality]. The Hague, Netherlands: Sociaal en Cultureel Planbureau. Retrieved June 25, 2004, from http://www.scp.nl/publicaties/boeken/905749518X.shtml.

Jan A.G.M. van Dijk is professor of communication science at the University of Twente, the Netherlands, Department of Communication. His teaching chair is called The Sociology of the Information Society. Van Dijk is investigating the social, cultural and political/policy issues of information and communication technology. Key publications in English are The Network Society (1999, 2006), Digital Democracy (2000), co-edited with Ken Hacker, The Deepening Divide, Inequality in the Information Society (2005) and Information and Communication Technology in Organizations (2005, with H. Bouwman, B. van den Hooff and L. van der Wijngaert).Van Dijk is an adviser of the European Commission. He also advises a number of Dutch ministries, city departments and political parties on issues related to ICT. 